\section{Empresa y Medio Ambiente}

Las empresas vienen cumpliendo normas internacionales para la conservación del medio ambiente dentro de los principios del Pacto Mundial, tomando especial preponderancia los conceptos como el agua, energía, desechos y gases de efecto invernadero, por la interrelación que existe entre las empresas para disminuir la contaminación ambiental y el encarecimiento de los costos de producción por el empleo adecuado de estos recursos

El agua es un elemento esencial para la sostenibilidad de la humanidad, recurso natural que en un mediano plazo podría verse limitado, la escasez y el costo para el mantenimiento del agua, harían que se incremente su precio, originando que los costos de producción de las empresas sea mayor, encareciendo los precios de venta del bien al consumidor.

Cuando hablamos de energía que son utilizadas por las empresas en nuestro país nos referimos a la energía eléctrica, al gas natural, los derivados del petróleo, el carbón y energía solar, siendo la más usada la energía eléctrica, por lo que el costo de la energía eléctrica incidirá en los costos de producción, permitiendo a los países que tienen la energía más cómoda tener los precios más competitivos en la región.

Las empresas vienen aplicando métodos para reducir el impacto que producen los desechos o residuos sólidos y líquidos, en la salud, y en el ambiente, tales como el reciclaje o la transformación de los residuos en energía, abono, etc., sin embargo los desechos que quedan terminan en los rellenos sanitarios y otros en el mar, ante esto los estados han dictados normas de regulación y sanciones a las empresas por contaminación.

Los gases de efecto invernadero es producto del proceso de transformación, que debe ser controlado, por lo que algunas empresas han comenzado a medir la cantidad de gases que produce las cuales dañan la atmosfera, de acuerdo al resultado de la cantidad de gases producidos se deben establecer medidas preventivas o de reducción y su consecuente incremento de los precios de venta del producto.

La Organización de las Naciones Unidas, viene liderando los acuerdos globales en cuanto al cuidado del medio ambiente, estableciendo algunos beneficios económicos a instituciones y empresas para que reduzcan el nivel de contaminación, así como el financiamiento de proyectos de investigación que permitan contribuir al desarrollo sostenible de la humanidad.

El estado es el responsable de hacer respetar las normas internacionales sobre el cuidado del medio ambiente, para lo cual debe establecer benéficos económicos y tributarios a instituciones y empresas que reduzcan el nivel de contaminación, asimismo juntos estado y empresa, deben invertir en proyectos que permitan la sostenibilidad del agua en el tiempo, mediante la construcción de represas, promulgación de normas para 
regular su uso, educación para el empleo doméstico, control a las empresas en el uso del agua, residuos y emisión de gases.

Las organizaciones públicas y privadas, mediante convenios con las Universidades deben incentivar a los alumnos para que realicen trabajos de investigación orientados a presentar alternativas de empleo y reducción de los desechos, empleo y reducción de los costos de la energía y reducción de la emisión de gases, aportes que permitirá contribuir al cuidado del medio ambiente, reduciendo los costos de producción y convirtiendo a las empresas del país en las más competitivas en calidad y precio de la región.

Comité Editorial 